\title{
Water Depletion and Land Subsidence in Iran Using Gravity, GNSS, InSAR and Precise Levelling Data
}

\author{
Jacques Hinderer, Abdoreza Saadat, Hamideh Cheraghi, \\ Jean-Daniel Bernard, Yahya Djamour, Masoomeh Amighpey, \\ Seyavash Arabi, Hamidreza Nankali, and Farokh Tavakoli
}

\begin{abstract}
Population growth, coupled with the expansion of exploitation of groundwater resources for agricultural and industrial purposes, has led Iran to face the necessity of proper use and sustainable management of existing water resources. In this study we will use the existing valuable geodetic data (gravity, GNSS, precise levelling, InSAR) in Iran to better understand the surface deformation and gravity variations caused by underground water depletion attributed to drastic pumping. Based on repetition of first order precise leveling network of Iran, about 44 subsidence areas are identified and continuous data collected by the Iranian permanent GNSS and geodynamic network (IPGN), as well as InSAR data, indicate strong elevation changes in some parts of the country. GRACE satellite gravity solutions over Iran also show a general gravity decrease between 2002 and 2016. New absolute gravity campaigns were performed in Iran in 2017 and 2018 in the frame of the TRIGGER French-Iranian program. Several new absolute gravity stations were established and former stations, first measured between 2000 and 2007, were repeated showing that the gravity values of many stations have changed in time. Most of these changes indicate a gravity decrease mostly linked to mass deficit due to water depletion. On the contrary some stations show a large gravity increase that can be merely explained by land subsidence itself linked to water depletion by poroelastic effects.
\end{abstract}

Keywords

Absolute gravity $\cdot$ GNSS $\cdot$ InSAR $\cdot$ Land subsidence $\cdot$ Precise levelling $\cdot$ Water depletion

\section{Introduction}

Land subsidence is one of the major hazards in Iran. It usually occurs due to both man-made and natural causes (Motagh et al. 2008). Today, due to the over-extraction of underground water over large parts of the country, the

J. Hinderer $(\bowtie) \cdot$ J.-D. Bernard

EOST (Ecole et Observatoire des Sciences de la Terre)/Institut de Physique du Globe de Strasbourg, UMR7516 CNRS/Université de Strasbourg, Strasbourg Cedex, France

e-mail: jhinderer@unistra.fr

A. Saadat $\cdot$ H. Cheraghi $\cdot$ Y. Djamour $\cdot$ M. Amighpey $\cdot$ S. Arabi $\cdot$ H. Nankali · F. Tavakoli

National Cartographic Center (NCC) Meraj Avenue, Tehran, Iran range of subsidence has expanded to urban areas. This can lead to damage of buildings or other constructions and lead to large costs for compensation. To avoid this, subsidence areas should be identified at an early stage. Here, geodetic measurement such as gravity, precise levelling and GNSS data along with InSAR techniques can help us to detect the surface deformation with accurate evaluation of the magnitude, distribution and spatial pattern of land subsidence. In this paper, we investigate the use of geodetic data to monitor the ongoing land subsidence over the country. According to the report of Geodesy and Land Surveying Department of the National Cartographic Center (NCC) of Iran, the repetition of the first-order leveling network has led to detect more than 44 subsidence areas, with a total extension of at least $1,200 \mathrm{~km}^{2}$ estimated (Amighpey and Arabi 2016), which indicates that vast areas of the country are affected by the phenomenon 
of subsidence. Besides to the leveling technique we also considered the InSAR (Interferometric synthetic aperture radar) method with the help of Sentinel 1 data for the recent 2017-2019 period. Finally the analysis of the time-series of permanent GNSS stations further confirms the importance of subsidence in many parts of Iran.

Another way to investigate water depletion is to estimate the changes in time of the gravity field. This can be done from space thanks to the GRACE mission which provides a view of the gravity changes at large scales (hundreds of $\mathrm{km}$ ) as well as at the Earth's surface where the measurements are of more local interest. Water depletion effects leading to a decrease in gravity are well known in Middle East (Longuevergne et al. 2013; Voss et al. 2013; Joodaki et al. 2014; Darama 2014; Forootan et al. 2017). The repetition of absolute gravity campaigns between 2000 and 2018 shows that the gravity values of many stations have changed in time due to the vertical movements and/or water depletion in Iran.

It is interesting to note that any ground gravimeter will see two opposite effects linked to water depletion:

- the Newtonian attraction of the water masses which is directly function of the water table height changes multiplied by porosity (less water less gravity) $(42 \mu \mathrm{Gal} / \mathrm{m}$ of water)

- the effect of uplift or subsidence of the ground because of the vertical gradient $(-306 \mu \mathrm{Gal} / \mathrm{m}$ for the Free Air Gradient) (subsidence leads to gravity increase and vice versa).

Since subsidence is usually linked to underground water depletion in any poroelastic model (Burbey 2001), the two effects are opposite in sign but, according to the site characteristics, one effect can be larger than the other leading to gravity increase or decrease.

Finally let us mention that, on the contrary to surface gravity, GRACE space gravity is not sensitive to ground displacement as discussed for instance in Crossley et al. (2012).

\section{Geodetic and Gravity Data}

National Cartographic Center (NCC) of Iran is responsible for all activities in the field of mapping and surveying all over the country. For this purpose, the national geodetic reference frame it provided by the implementation of fundamental networks. These base networks are divided into different types, such as Precise Leveling network, Gravity network and, finally, Permanent Geodynamic and GNSS network. Iran belongs to a part of the globe with high seismic hazard. Establishing geodynamic networks can help us to better understand the Earth's crust movements and behavior of the tectonic deformation in different active parts of Iran (e.g. Djamour et al. 2010). The objectives of implementation of Iranian permanent geodynamic and GNSS network (IPGN) are mainly a better understanding of tectonic deformation and the estimation of potential for future earthquake hazards.

Measurements of the first order precise levelling network of Iran include more than 33,000 km, carried out from 1980 up to 1996 using optical levels. After that, these measurements were repeated in 2001 and were completed in 2009 using new digital levels. The levelling networks of Iran are categorized in three orders (all exceed 90,000 km) based on the scopes, specification and achieved precision.

We applied Sentinel-1 interferometric wide-swath images covering the 2017-2019 period with small baseline timeseries approach to estimate subsidence rate in Iran. The Sentinel-1 mission from ESA (European Space Agency) consists of two polar-orbiting satellites, operating day and night performing $\mathrm{C}$-band synthetic aperture radar imaging. The average velocities acquired from InSAR time series were projected onto vertical direction to compare with our geodetic results, assess the accuracy of them and validate them.

Absolute gravity campaigns have been done in Iran in the period 2000-2007 and some of these measurements could be repeated in 2017 and 2018 during more recent campaigns. Gravity measurements with absolute gravimeter FG5 type (Micro-g Solutions Inc.) were performed in Iran for three main applications: first to establish zero-order gravity network as fundamental points to extend gravity data in relative sense over the country and provide Iranian gravity calibration line, second to use gravity to have more insight in the determination of vertical motion in tectonic areas and finally to investigate the continental water changes in the arid region of Iranian central desert.

The zero-order gravity network of Iran, which includes 35 stations throughout the country, was designed in 1997. Most of its stations were measured by absolute gravimeter FG5206, in collaboration with the University of Montpellier-II and Strasbourg during 2000 to 2007 in several field campaigns with $0.001-0.002 \mathrm{mGal}$ level of uncertainty (Hinderer et al. 2003). After that, the first and second order gravity networks, including 670 and 1909 stations respectively, were also extended over the country by connecting to the zero-order gravity network in relative sense using relative gravimeters CG-3 M and CG5. In order to do regional gravity field modelling, a $5 / \times 5$ / dense gravity data including 20,437 points has been measured in Iran.

We finally also considered gravity data at monthly rate from the GRACE (Gravity Recovery and Climate Experiment) twin satellites to point out the large scale (typically $400 \mathrm{~km} \times 400 \mathrm{~km}$ pixels) gravity changes over Iran from 2002 to 2016 . 
Iran

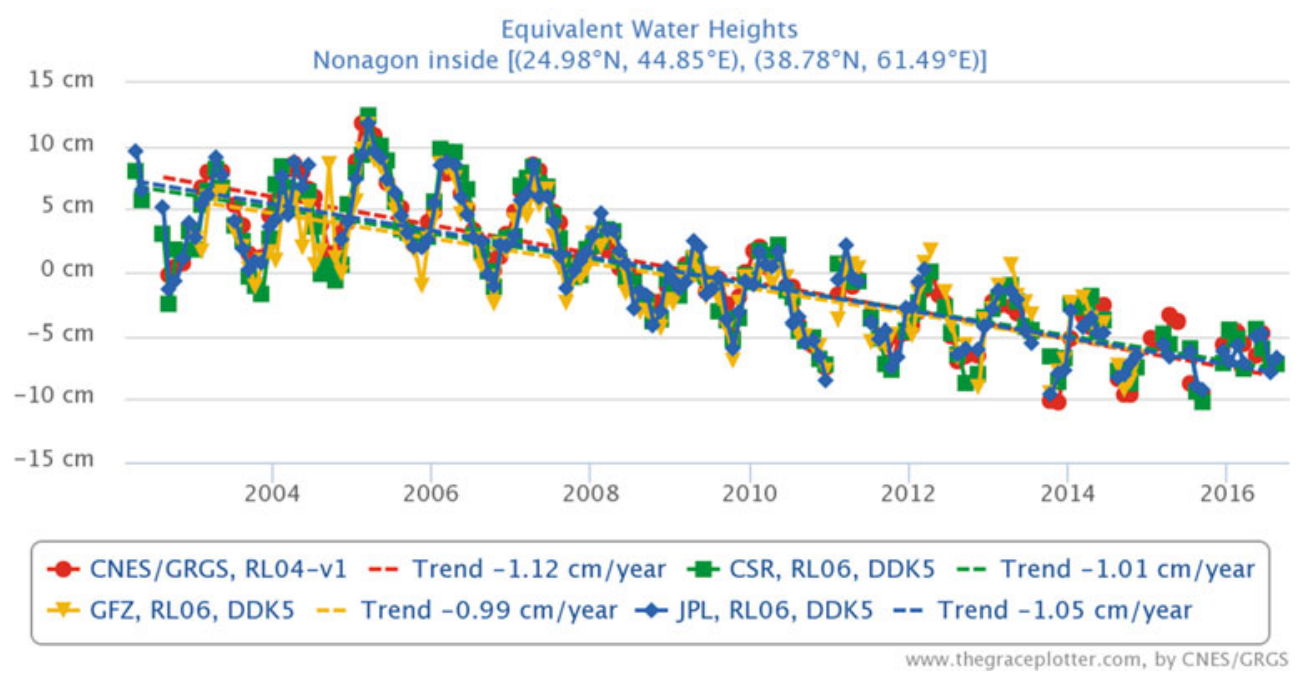

Fig. 1 GRACE observations of the water depletion in Iran for the 2002-2016 period

\section{$3 \quad$ Results}

We present now the main results first in gravity from space and ground (AG) and second from the three geodetic techniques available to us (GNSS, leveling, InSAR). Everytime land subsidence was evidenced by GNSS and leveling, InSAR data were also considered to provide the most accurate vertical ground motion to correct surface gravity.

\subsection{Space Gravimetry (GRACE)}

Figure 1 shows the gravity decrease in Iran from 2002 to 2016 as observed by GRACE satellite gravity observations. Different solutions from different processing centers (CNES/GRGS, CSR, GFZ, JPL) are presented that agree both on the annual signal and on the long term trend that amounts to a value close to $-1 \mathrm{~cm} /$ year (in terms of equivalent water height).

\subsection{Absolute Gravity}

Several absolute gravity measurements done in the first epoch (2000-2007) could be repeated in 2017 and 2018 all over Iran. Figure 2 shows the results that merely can be divided into two different zones: gravity decrease in the northern part ranging from $-0.8 \mu \mathrm{gal} / \mathrm{year}$ to $-5.9 \mu \mathrm{gal} / \mathrm{year}$ and gravity increase in the southern part ranging from 0.8 $\mu$ gal/year to $13 \mu \mathrm{gal} / \mathrm{year}$.

\subsection{Geodetic and InSAR Results}

Figure 3 summarizes all the stations exhibiting subsidence with estimated vertical displacement rates (in $\mathrm{mm} / \mathrm{year}$ ) of permanent IPGN observations and repeated leveling measurements in Iran. These geodetic results have been used to locate potential land subsidence areas in Iran where InSAR data were investigated to detect and monitor the spatial and temporal pattern of subsidence (Motagh et al. 2017). We processed Sentinel-1 images where IPGN and leveling results showed land subsidence.

Figure 4 shows the numerous subsidence regions in Iran and the maximum rate of subsidence (in $\mathrm{mm} /$ year) in each region found from InSAR data.

\section{Discussion}

The average water depletion all over Iran found from GRACE data of the order of $1 \mathrm{~cm} /$ year (see Fig. 1) and confirms previous studies (Forootan et al. 2014; Afshar et al. 2016; Khaki et al. 2018). In terms of gravity, this amounts to a decrease of $0.42 \mu \mathrm{Gal} /$ year if elasticity of the Earth is neglected. However this large scale mean rate is different from the rate derived from surface gravity measurements since 1/satellite data are not sensitive to the surface vertical motion on the contrary to ground data (see Eq. 1 in Crossley et al. 2012) and 2/local ground water decline can be large (a few tens of $\mathrm{cm} / \mathrm{year}$ ) as shown by piezometric measurements in Iran (Haghighi and Motagh 2019). 


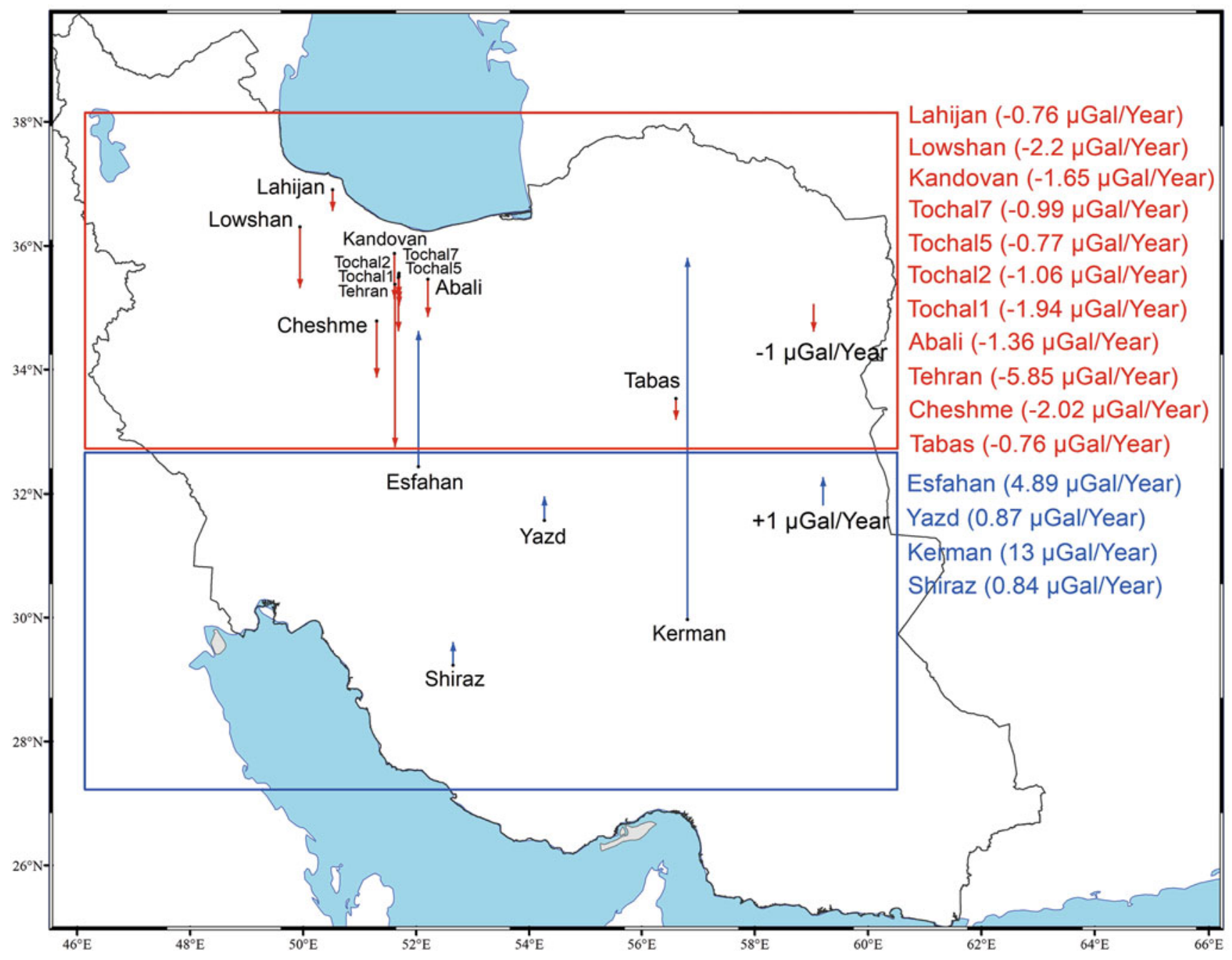

Fig. 2 Absolute gravity changes (in $\mu \mathrm{Gal} /$ year) resulting from the 2017-2018 repetition of the Iranian fundamental network

Despite the different time periods of the results, the rate of the vertical displacements estimated from geodetic tools are consistent with each other; for instance see the agreement between the GNSS stations (FHRJ, FDNG, NISH, GRGN, GGSH) and the closest respective leveling stations (CVDE, CUDC, BCBK, ASBA, AGHA). The comparison of Figs. 3 and 4 also shows the agreement between leveling stations and InSAR results in several regions like the Kerman one for instance (see below the specific values for Kerman station).

From our AG measurements we think that the gravity decreases seen in the northern part of Fig. 2 are mostly due to water depletion attraction with small contribution from ground subsidence. The largest gravity decrease is found for Tehran $(-5.8 \mu \mathrm{Gal} /$ year $)$ but -1 to $-2 \mu \mathrm{Gal} /$ year effects are frequent. A typical example of the northern part is the Tehran station where the numerous repeated AG measurements since 2000 indicated a large decrease rate of several $\mu \mathrm{Gal} /$ year (that seems even to accelerate in recent years) due to underground water depletion, well documented by various piezometric records in the vicinity of the station, although there is no significant vertical displacement (less than $4 \mathrm{~mm} /$ year). The Tehran station does not fall into the main subsidence bowl in Western Tehran as presented by Haghighi and Motagh (2019) which might be the reason why the subsidence does not affect the gravity measurement.

On the contrary, the gravity increases seen in the southern part of Fig. 2 are mostly due to ground subsidence linked to water depletion with only a small contribution from attraction. The largest gravity effects are for Espahan (+5 $\mu \mathrm{Gal} /$ year) and Kerman $(+13 \mu \mathrm{Gal} /$ year). A typical example of the southern part is the Kerman station exhibiting large subsidence rates: - $3.9 \mathrm{~cm} /$ year from InSAR (20172019), - $4.3 \mathrm{~cm} /$ year from GPS (2011-2017) and $4.0 \mathrm{~cm} /$ year from leveling (1987-2006) while gravity increases by $13 \mu \mathrm{Gal} / \mathrm{year}$. We refer to Setyawan et al. (2015) for a similar study in Indonesia combining gravity and height changes due to declining groundwater. Taking into account a subsidence rate close to $4 \mathrm{~cm} /$ year and a gravity increase 


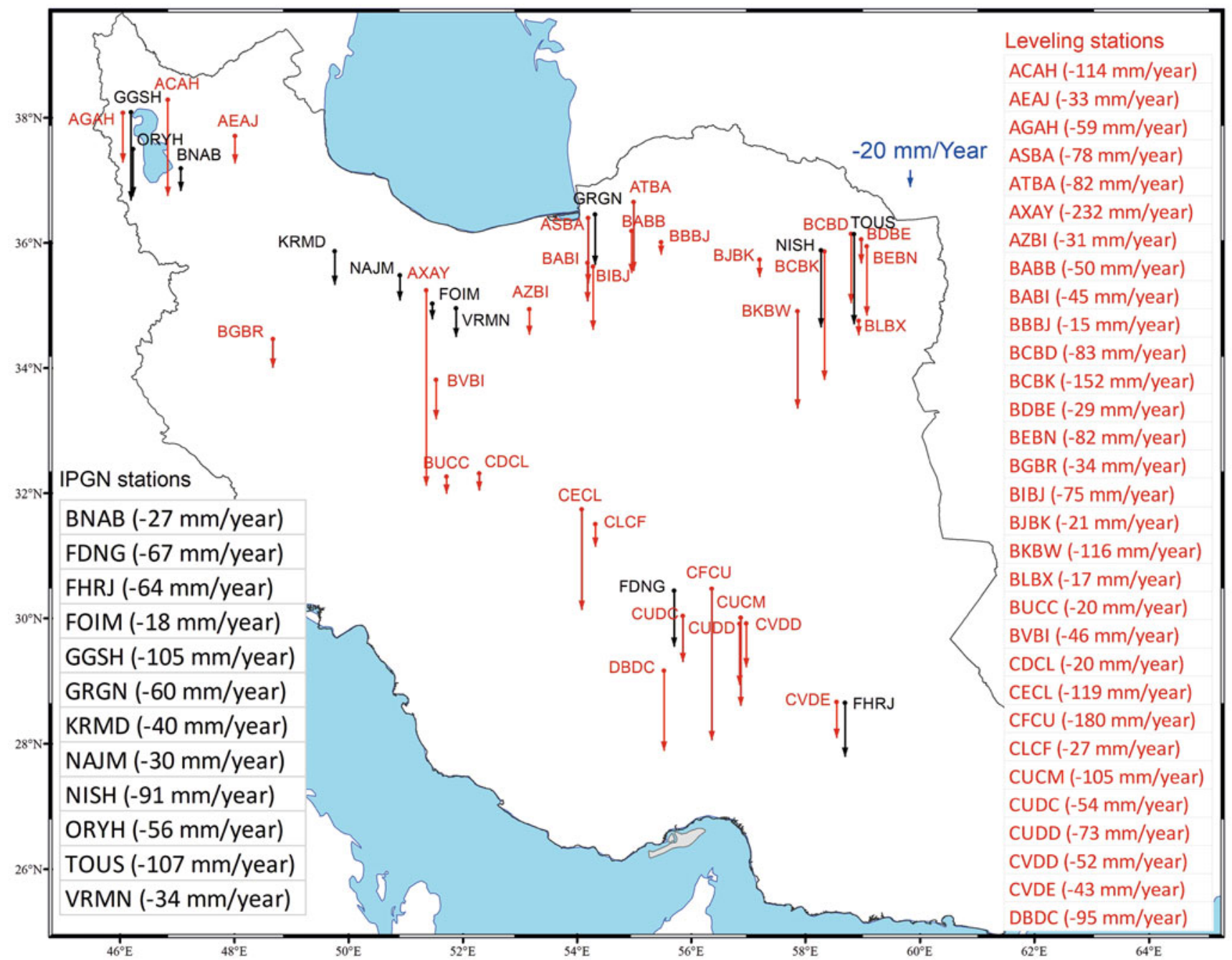

Fig. 3 Subsidence rate of IPGN and Leveling stations. The black arrows show the IPGN rates and the red ones indicate the estimated subsidence rate of leveling stations

of $13 \mu \mathrm{Gal} / \mathrm{year}$ would lead to a gravity/height ratio of $-3.2 \mu \mathrm{Gal} / \mathrm{cm}$ which is very close to measured free air gradient $(-3.1 \mu \mathrm{Gal} / \mathrm{cm})$; however there might also be an attraction effect (gravity decrease) due to water depletion which would enhance this ratio. This effect is yet unknown because of the lack of piezometric records in the vicinity.

\section{Conclusion}

Repetitive and continuous observations based on the Iranian Fundamental Geodetic networks indicate a high rate of subsidence in some parts of the country. These changes are more than a few decimeters per year in some areas. Most subsidence areas in Iran are located in plains and centers with known over-extraction of underground water. This reveals that there is a need for better management of groundwater resources. Geodetic observations (leveling,
GNSS, inSAR) yield very accurate data for monitoring the deformation of the Earth's crust. Absolute gravity as well as space gravimetry data (GRACE) reveal significant longterm gravity changes related to water depletion. By combining these data with other data from geological resources, valuable information can be obtained for decision making. Combining these data with radar interferometry techniques along with other geological resources can help authorities in crisis management to make better decisions. There is a need to repeat the zero-order and hydrological stations in Central Iran in the upcoming years (in the frame of TRIGGER French-Iranian program).

\section{References}

Afshar AA, Joodaki GR, Sharifi MA (2016) Evaluation of groundwater resources in Iran using GRACE gravity satellite data. J Geomatic Sci Technol 5(4):73-84. http://jgst.issge.ir/article-1-381-en.html 


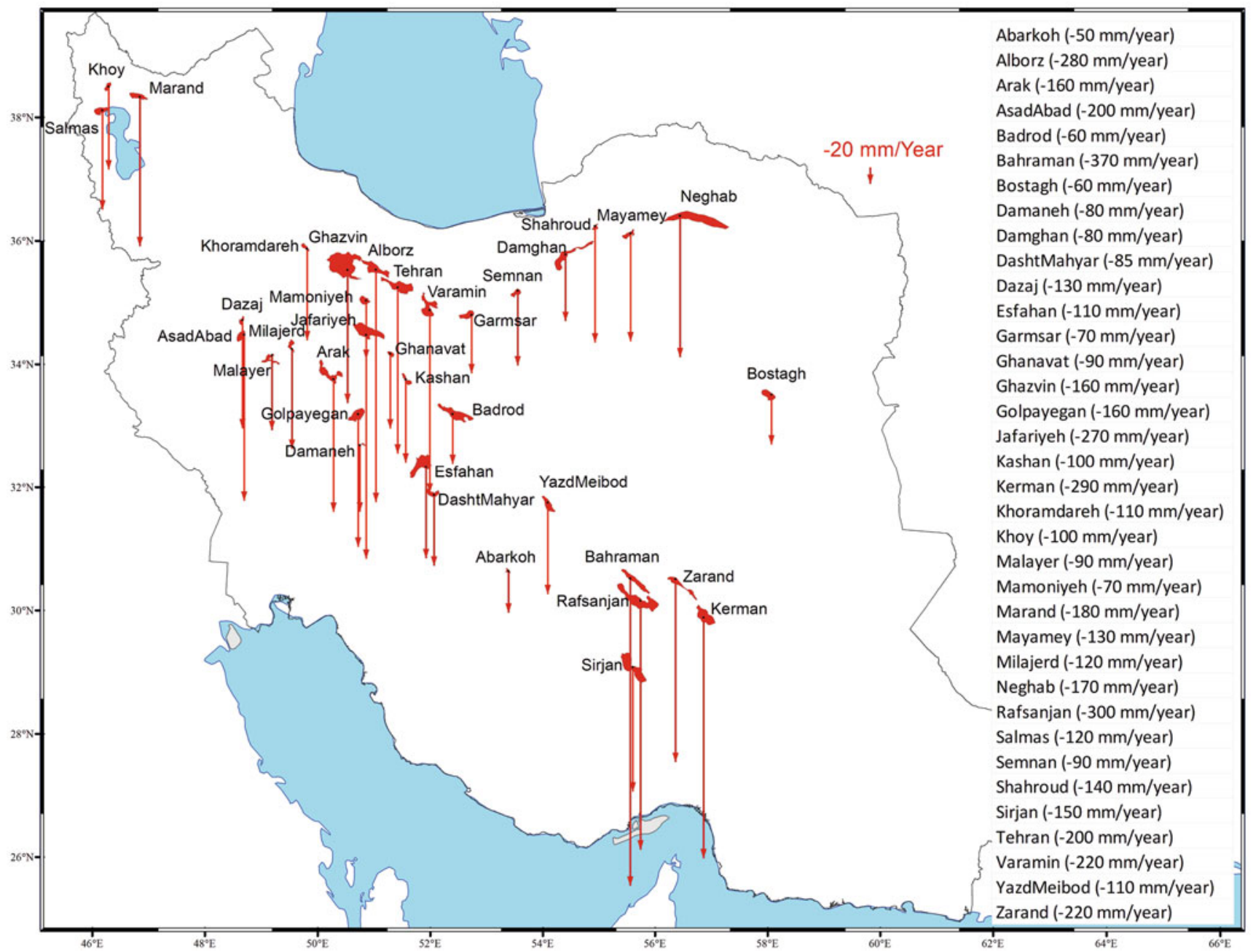

Fig. 4 The subsidence area of some plains in Iran (red polygons) from InSAR results obtained by processing Sentinel-1 data between 2017 and 2019. The arrows show the maximum vertical displacement rate in each region

Amighpey M, Arabi S (2016) Studying land subsidence in Yazd province, Iran, by integration of InSAR and levelling measurements. Remote Sensing App Soc Environ 4:1-8

Burbey TJ (2001) Stress-strain analyses for aquifer-system characterization. Ground Water 39(1):128-136

Crossley D, de Linage C, Boy J-P, Hinderer J, Famiglietti J (2012) A comparison of the gravity field over Central Europe from superconducting gravimeters, GRACE, and global hydrological models, using EOF analysis. Geophys J Int 189:877-897

Darama Y (2014) Comment on "Groundwater depletion in the Middle East from GRACE with implications for transboundary water management in the Tigris-Euphrates-Western Iran region" by Katalyn A. Voss et al. Water Resour Res 50:754-757. https://doi.org/10.1002/ 2013WR014084

Djamour Y, Vernant P, Bayer R, Nankali HR, Ritz J-F, Hinderer J, Hatam Y, Luck B, Le Moigne N, Sedighi M, Khorrami F (2010) GPS and gravity constraints on continental deformation in the Alborz mountain range, Iran. Geophys J Int 183:1287-1301. https://doi.org/ 10.1111/j.1365-246X.2010.04811.x

Forootan E, Rietbroek R, Kusche J, Sharifi MA, Awange J, Schmidt M, Omondi P, Famiglietti J (2014) Separation of large scale water storage pat- terns over Iran using GRACE, altimetry and hydrological data. J Remote Sens Environ 140:580-595. https://doi.org/10.1016/ j.rse.2013.09.025
Forootan E, Safari A, Mostafaie A, Schumacher M, Delavar M, Awange J (2017) Large-scale total water storage and water flux changes over the arid and semi- arid parts of the middle east from GRACE and reanalysis products. Surv Geophys 38:591-615. https://doi.org/10. 1007/s10712-016-9403-1

Haghighi MH, Motagh M (2019) Ground surface response to continuous compaction of aquifer system in Tehran, Iran: results from a long-term multi-sensor InSAR analysis. Remote Sens Environ 221(2019):534-550

Hinderer J, Sedighi M, Bayer R, Ghazavi K, Amalvict M, Luck B, Nilforoushan F, Masson F, Peyret M, Djamour Y, Kouhzare A (2003) The absolute gravity network in Iran: an opportunity to analyse gravity changes caused by present-day tectonic deformation. In: Proc. IMG-2002 (Instrumentation and metrology in Gravimetry), vol 22. Cahiers du Centre Européen de Géodynamique et de Séismologie, Luxembourg, pp 137-141

Joodaki G, Wahr J, Swenson S (2014) Estimating the human contribution to groundwater depletion in the middle east, from GRACE data, land surface models, and well observations. Water Resour Res 50:26792692. https://doi.org/10.1002/2013WR014633

Khaki M, Forootan E, Kuhn M, Awange J, van Dijk AIJM, Schumacher M, Sharifi MA (2018) Determining water storage depletion within Iran by assimilating GRACE data into the W3RA hydrological model. Adv Water Resour 114(2018):1-18 
Longuevergne L, Wilson C, Scanlon BR, Cretaux JF (2013) GRACE water storage estimates for the Middle East and other regions with significant reservoir and lake storage. Hydrol Earth System Sci 17(12):4817-4830. https://doi.org/10.5194/hess-17-4817-2013

Motagh M, Walter TR, Sharifi MA, Fielding E, Schenk A, Anderssohn J, Zschau J (2008) Land subsidence in Iran caused by widespread water reservoir overexploitation. Geophys Res Lett 35:L16403. https://doi.org/10.1029/2008GL033814

Motagh M, Shamshiri R, Haghshenas Haghighi M, Wetzel H, Akbari B, Nahavandchi H, Roessner S, Arabi S (2017) Quantifying groundwater exploitation induced subsidence in the Rafsanjan plain, south- eastern Iran, using InSAR time-series and in situ measurements. Eng Geol 218:134-151

Setyawan A, Fukuda Y, Nishijima J, Kazama T (2015) Detecting land subsidence using gravity method in Jakarta and Bandung area, Indonesia. Procedia Environ Sci 23:17-26

Voss KA, Famiglietti JS, Lo M, de Linage C, Rodell M, Swenson SC (2013) Groundwater depletion in the Middle East from GRACE with implications for transboundary water management in the TigrisEuphrates-Western Iran region. Water Resour Res 49:904-914. https://doi.org/10.1002/wrcr.20078

Open Access This chapter is licensed under the terms of the Creative Commons Attribution 4.0 International License (http://creativecommons.org/ licenses/by/4.0/), which permits use, sharing, adaptation, distribution and reproduction in any medium or format, as long as you give appropriate credit to the original author(s) and the source, provide a link to the Creative Commons license and indicate if changes were made.

The images or other third party material in this chapter are included in the chapter's Creative Commons license, unless indicated otherwise in a credit line to the material. If material is not included in the chapter's Creative Commons license and your intended use is not permitted by statutory regulation or exceeds the permitted use, you will need to obtain permission directly from the copyright holder.

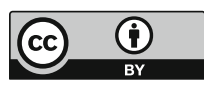

